\title{
Alcohol intake among adolescent students and association with social capital and socioeconomic status
}

\author{
Consumo de bebida alcoólica por estudantes adolescentes \\ e sua associação com capital social e condição socioeconômica
}

Kelly Oliva Jorge ${ }^{1}$

Paula Cristina Pelli Paiva ${ }^{2}$

Efigênia Ferreira e Ferreira ${ }^{3}$

Miriam Pimenta do Vale ${ }^{4}$

Ichiro Kawachi ${ }^{5}$

Patrícia Maria Zarzar ${ }^{4}$

\footnotetext{
${ }^{1}$ Departamento de Odontologia, Universidade Vale do Rio Verde de Três Corações. Av. Amazonas 3200, Prado. 30240-350 Belo Horizonte MG Brasil. kellyoliva@yahoo.com.br ${ }^{2}$ Departamento de Odontologia, Faculdade de Ciências Biológicas e da Saúde, Universidade Federal dos Vales do Jequitinhonha e Mucuri. Diamantina MG Brasil.

${ }^{3}$ Departamento de Saúde Pública, Faculdade de Odontologia, Universidade Federal de Minas Gerais (UFMG). Belo Horizonte MG Brasil.

${ }^{4}$ Departamento de Odontopediatria e Ortodontia, Faculdade de Odontologia, UFMG. Belo Horizonte MG Brasil. ${ }^{5}$ Department of Social and Behavioral Sciences, Harvard School of Public Heath and Medical School. Cambridge Massachusetts United States of America.
}

\begin{abstract}
The aim was to evaluate the prevalence of alcohol consumption, binge drinking and their association with social capital and socioeconomic factors among Brazilian adolescents students. A cross-sectional study was carried out with a randomly selected representative sample of 936 adolescents aged 15 to 19 years. Information on alcohol consumption, social capital and socioeconomic status was collected using the Alcohol Use Disorders Identification Test, the Integrated Questionnaire for the Measurement of Social Capital and Social Vulnerability Index, respectively. The prevalence of alcohol consumption was 50.3\% and binge drinking $36 \%$ the last year. Adolescents who reported believing that people in their community could help solve a collective problem (with the water supply) and those classified as having high social vulnerability had lower likelihood of binge drinking ( $P R=0.776$ [95\%CI:0.620 to 0.971] and $P R=0.660$ [95\%CI:0.542 to 0.803], respectively). The prevalence of alcohol consumption and binge drinking the last year is high among participants. Those with higher socioeconomic status as well as lower perceptions of community capital social are more likely to display binge-drinking behavior.
\end{abstract}

Key words Social capital, Binge drinking, Socioeconomic factors, Adolescents
Resumo O objetivo foi avaliar prevalência do consumo de bebida alcoólica e associação com o capital social e fatores socioeconômicos em estudantes adolescentes. Estudo transversal realizado com amostra representativa aleatória de 936 adolescentes de 15 a 19 anos. Informações sobre o consumo de álcool no último ano, capital social e condição socioeconômica foram levantadas utilizando-se o Teste de Triagem para Abordar Problemas Relacionados com Álcool (AUDIT), Questionário Integrado para Medir Capital Social e Índice de Vulnerabilidade Social, respectivamente. Prevalência de consumo de bebida alcoólica foi de 50,3\% e consumo abusivo de álcool $36,0 \%$, no último ano. Os adolescentes que relataram acreditar que as pessoas em sua comunidade possam ajudar a resolver problemas coletivos (como o abastecimento de água) e os classificados como pertencentes ao grupo de alta vulnerabilidade social apresentaram menor probabilidade de consumo abusivo de álcool $(R P=[I C 95 \%: 0,620$ 0,971] 0,776 e PR = [IC95\%:0,542-,803] 0,660). As prevalências de consumo de bebidas alcoólicas e consumo abusivo de álcool no último ano foram altas. Adolescentes com melhor condição socioeconômica e menor percepção do capital social foram mais propensos a apresentar um comportamento de consumo abusivo de bebidas alcoólicas.

Palavras-chave Capital social, Bebedeira, Fatores socioeconômicos, Adolescentes 


\section{Introduction}

Adolescence is a stage of life characterized by great discoveries and emotional instability. It is considered a critical period for the development of personal and interpersonal abilities, and is a stage of life when individuals are particularly susceptible to social influences. Depending on the social context, teens may adopt behavior that is either protective or a risk to their health. Among the behaviors of risk are the use of alcohol and binge drinking. Binge drinking is defined as having five or more drinks on a single occasion for men, and four drinks for women ${ }^{2}$. This type of behavior is common among adolescents and poses a risk of additional problems such as sexual risk behavior, dating violence, poor school performance, involvement in crime, unintentional injuries, and abuse of other substances ${ }^{3}$. Several factors determine drinking behavior among adolescents, including the need for socialization, relationships with the opposite sex, subjective expectations and norms and, above all, family and social contexts. Social relations can exert either a beneficial influence on behavior or serve as a source of tension, stress and conflict, especially in adolescence $e^{4}$.

Social capital relates to the characteristics of social organization, such as trust and relationship networks ${ }^{5}$. Social capital is increasingly studied for its contextual influence on health, with emphasis given to the characteristics of the social environment, based on the idea that relationships exert an important impact on health and wellbeing, such as the ability of a community to engage in collective action through the existence of cohesive relationships. Social capital can be considered a determinant of the health of a population, as health is influenced by demographic, socioeconomic and behavioral factors, as well as the ability to cope with problems ${ }^{6}$. Social capital has generally been characterized as social participation and trust, which are considered mutually dependent and are hypothesized to enhance one another. To some extent, however, social participation has transformed into much more ideologically narrowly defined single-issue movements, formal and informal social networks and activities entailing a much smaller "radius of trust". Volunteer organizations with different objectives and degrees of formalization represent a countervailing influence on social disintegration in modern society, and the number of such organizations in a community provides an indication of the degree of collectivity in civil society.
Volunteer work is particularly prized due to the fact that it allows individuals to reach their goals through dialog and negotiation, leading to the development of civic practices that are beneficial to the functioning of democracy, including social participation, reciprocal trust, cooperation and mutual tolerance. Beyond their specific goals, civic groups offer the opportunity for cooperation and the exchange of knowledge among members. Behavior is molded by social and community contexts and the manner in which an individual relates with his/her community plays an important role in health ${ }^{7}$.

It is hypothesized that social capital is linked to the health of the population by the direct psychosocial mechanisms, norms and values associated with health-related behavior, crime, the degree of social disorganization and access to health care and amenities ${ }^{8}$. However, few studies have examined the relationships between civic cooperation, solidarity and collective efficacy and the health status of adolescents.

The aim of the present study was to evaluate the prevalence of binge drinking and its association with socioeconomic factors and social capital among adolescents in the city of Belo Horizonte, Brazil. A cross-sectional survey and dataset was used to test the hypothesis that higher levels of community social capital (measured by individual perceptions of community solidarity and collective action) may be associated with lower binge drinking among adolescents.

\section{Methods}

\section{Study design and participants}

A cross-sectional survey was carried out with a randomly selected representative sample of 936 adolescents aged 15 to 19 years attending public and private schools in the city of Belo Horizonte (the state capital of Minas Gerais, Brazil) in 2010.

The city has approximately two million inhabitants and is geographically divided into nine administrative districts. The sample was selected using a stratified cluster sampling method. To represent the real distribution of 15 to 19 -yearold students in Belo Horizonte, two-stage stratified cluster sampling proportional to the administrative districts was used. The first stage was the random selection of two schools, one public and one private, from each of the nine districts (giving a total of 18 schools). Three public schools refused to participate due to time constraints 
linked to a teachers' strike earlier that year and were replaced by others through an additional random selection by lots. The second stage was the random selection of 34 of the 65 classrooms in the 18 schools. All the students belonging to randomly selected classes were invited to participate. The sample size was calculated based on a $4.0 \%$ standard error, a $95.0 \%$ confidence interval, and a $50 \%$ prevalence rate of consumed alcoholic beverages. The minimum sample size required was determined at 600 individuals, to which $20.0 \%$ was added to compensate for possible non-responses $(\mathrm{n}=720)$. A design effect of 1.3 was applied to increase precision, as multistage, rather than simple random sampling, was employed. Thus, the sample was comprised of 936 adolescents. The test power was $80.0 \%$.

In the case of the complex sample, estimates of prevalence and confidence intervals were calculated using the "Complex Sample" module of the Statistical Package for the Social Sciences (SPSS), which considers the study design and sample weights. The sample weights were calculated for each individual by calculating the inverse of the probability of inclusion of each individual in the study. The probability was obtained by multiplying the inclusion probabilities in the stages of random selection (schools and rooms) and the response rate.

\section{Collection of data}

The self-administered questionnaires were distributed in the classroom by a researcher and assistant and collected immediately after completion. The students were told that the questionnaires would be anonymous and the responses would be treated confidentially. To guard against biases due to variability in reading proficiencies, the principal investigator (K.O.J.) read each question aloud. Students could refuse to participate and return the incomplete questionnaires in the envelopes. Information on social capital and alcohol consumption was collected using two validated, self-administered questionnaires - the Integrated Questionnaire for the Measurement of Social Capital (SC-IQ) and Alcohol Use Disorders Identification Test (AUDIT).

A pilot study was conducted among 101 adolescents to cognitively test both self-administered questionnaires (SC-IQ and AUDIT) and determine the need for changes, as suggested by the adolescents.

\section{Socioeconomic status}

The Social Vulnerability Index (SVI) was used for the socioeconomic classification of adolescents in the sample? . This index measures social exclusion in each neighborhood the city of Belo Horizonte. The city hall database of SVI scores for each district was used to categorize the social vulnerability of the participants based on the address of each student. The SVI has 20 variables grouped into five "dimensions of citizenship: environmental (access to housing and basic infrastructure); cultural (access to education); economic (access to income and employment); legal (access to legal assistance); and survival security (access to health, food security and welfare $)^{10}$. Scores range from 0 to 1 , with higher values denoting worse community conditions or greater vulnerability to social exclusion within the community in question. The SVI was dichotomized as more vulnerable (social classes 1 and 2) versus less vulnerable (social classes 3, 4 and 5).

Mother's schooling was used as an indicator of individual socioeconomic status due to its association with alcohol consumption/binge drinking in adolescents ${ }^{11}$. This variable was determined based on the responses of students to a question addressing the number of years of schooling their mothers had received. Respondents who reported that their mothers had studied for a period of 0 to 7 years were coded as 0 and those who reported 8 or more years were coded as 1 . The median was used as the cut-off point.

Type of school (public versus private) was also used as an additional socioeconomic indicator. Although type of school is a crude assessment, wealthy adolescents in Brazil enroll in private schools as most Brazilian public schools have fewer educational resources. Moreover, a recent study concluded that type of school is a useful socioeconomic indicator in studies involving Brazilian children ${ }^{12}$.

\section{Social Capital}

The SC-IQ is an instrument to measure social capital developed and validated by the World Bank ${ }^{13}$ and has been previously administered to Brazilian adolescents ${ }^{14}$. Each item was taken from previous surveys on social capital and the questionnaire has demonstrated both reliability and validity. The SC-IQ consists of 27 items distributed among six subscales (Groups and Networks; Trust and Solidarity; Collective Action 
and Cooperation; Information and Communication; Cohesion and Social Inclusion; and Empowerment and Political Action). In the present study, the Trust/Solidarity and Collective Action/ Cooperation subscales were used for the assessment of social behavior related to involvement in community. These two domains are composed of seven questions: "Generally speaking, would you say that most people can be trusted, or that you can't be too careful in your dealings with other people?; In general, do you agree or disagree with the following statements?; Most people in this village/neighborhood are willing to help if you need it.; In this village/neighborhood, one has to be alert or someone is likely to take advantage of you. How much do you trust local government officials; How much do you trust central government officials; If a community project does not directly benefit you, but has benefits for many others in the village/neighborhood, would you contribute time or money to the project?; In the past 12 months, have you worked with others in your village/neighborhood to do something for the benefit of the community?; If there was a water supply problem in this community, how likely is it that people will cooperate to try to solve the problem?".

\section{Assessment of alcohol intake and binge drinking}

AUDIT is a simple method of screening for excessive drinking and consists of ten questions inquiring about recent alcohol use, symptoms of alcohol dependence and alcohol-related problems. This measure has been validated for use in Brazil. The instrument helps identify whether an individual exhibits hazardous (or risky) drinking, harmful drinking or alcohol dependence. For this study, the AUDIT C (the first 3 questions of the AUDIT instrument related to the frequency and amount of alcohol consumed) was also used due to the fact that this measure can be effectively employed as a "stand-alone" screening measure to detect hazardous drinking among adolescents ${ }^{15}$. The third item on the questionnaire was chosen as the dependent variable in the bivariate and multivariate analyses due to its importance in assessing the frequency of heavy drinking. The respondents were asked, "How often do you have five or more drinks on one occasion?"16,17.

\section{Statistical analysis}

Data analysis was performed using the Statistical Package for Social Sciences (SPSS for Windows, version 17.0, SPSS Inc, Chicago, IL, USA). Descriptive and bivariate analyses were carried out using the chi-squared test $(\mathrm{p}<0.05)$. Poisson logistic regression was used in the multivariate analysis. The criterion for inclusion in the model was a 2 -tailed significance value of $p<0.20$ in bivariate analysis.

\section{Ethical considerations}

This study was approved by the Human Research Ethics Committee of the Universidade Federal de Minas Gerais (the Federal University of Minas Gerais) (Brazil) in accordance with the guidelines of the Declaration of Helsinki. Authorization was obtained from the schools to undertake the research. The participants and their parents/guardians signed a statement of informed consent. The participants were assured anonymity and confidentiality in their answers.

\section{Results}

A total of 936 adolescents aged 15 to 19 years were randomly selected to represent the population of schoolchildren in the city of Belo Horizonte, Brazil. The final sample consisted of 891 adolescents (mean age: $16.3 \pm 1$ years; 352 males [39.5\%] and 539 females [60.5\%]) enrolled in public (80.5\%) and private $(19.5 \%)$ schools. Non-responses totaled $4.8 \%(\mathrm{~N}=45$ adolescents) and were due to the incomplete filling out of questionnaires.

The frequency of alcohol consumption (How often do you drink alcoholic beverages?) among those who reported drinking alcoholic beverages less than once a month to more than four times a week was $50.3 \%(n=448)$. A total of 732 adolescents $(82.2 \%)$ reported low-risk alcohol consumption, while $158(17.7 \%)$ reported hazardous use to possible dependence.

With respect to binge drinking (How often do you have five or more drinks on one occasion?), 321 of adolescents (36\%) reported a frequency ranging from less than monthly to almost every day. No statistically significant difference was found between males (38.9\%) and females (34.1\%) with regard to binge drinking. Among the students from private schools, $47.1 \%$ reported having five or more drinks on a single occasion, whereas the corresponding prevalence 
among students in public schools was 33.3\% (p $=0.001$ ). There was a higher prevalence of binge drinking among adolescents whose mothers had a higher level of schooling ( $\mathrm{p}=0.002)$. Among those who reported never binge drinking $(\mathrm{n}=$ 570), 338 (59.3\%) were classified as being more socially vulnerable; the difference between socioeconomic groups was significant $(\mathrm{p}<0.001)$ (Table 1).

While $41.7 \%$ of the adolescents participating in community activities reported having consumed alcoholic beverages, the majority of these adolescents $(58.3 \%)$ reported not engaging in binge drinking $(\mathrm{p}=0.020)$. A willingness to contribute time or money to community projects was not significantly associated with binge drinking. Among adolescents who answered positively to the possibility of people cooperating to solve a collective problem that affected the entire community - specifically, a problem related to the public water supply - $(66.9 \%)$ reported not engaging in binge drinking $(\mathrm{p}=0.007)$ (Table 1$)$.

In Poisson regression analysis, higher social vulnerability and higher perceived collective efficacy (the ability of a community to solve common problems) remained significantly associated with a lower risk of binge drinking after control for gender and age ( $\mathrm{PR}=0.660$ [95\% CI: 0.542 to 0.803 ] and PR $=0.776$ [ 95\% CI: 0.620 to 0.971 ], respectively) (Table 2 ).

\section{Discussion}

The abusive consumption of alcoholic beverages among adolescents is an important public health issue. In the present study, the prevalence of alcohol consumption (a frequency ranging from less than once a month to four or more times a week) among students in the city of Belo Horizonte was high $(50.3 \%)$. This is in agreement with previous studies carried out in Brazil, which found prevalence values ranging from $24.2 \%$ to $78.0 \%{ }^{12,18}$.

Studies report that adolescents who drink tend to do so in public episodes of binge drinking $^{5,19,20}$. In the present study, the prevalence of binge drinking was $36.0 \%$, which is higher than the figure reported in a study carried out in the city of Sao Paulo (Brazil) ${ }^{21}$, in which $25 \%$ of a sample of 1808 students reported at least one episode of binge drinking in the previous 30 days. In a cross-sectional survey involving 48,155 students aged between 10 and 18 years enrolled in public schools in 27 large cities in Brazil, 4286 (8.9\%) had engaged in binge drinking in the pre- vious month ${ }^{22}$. A similar prevalence to that of the present investigation was reported in a previous sample of 2691 Brazilian students aged 14 to 19 years enrolled at private schools in the city of Sao Paulo, in which $34.5 \%$ of the participants reported engaging in binge drinking in the previous 30 days $^{12}$. The characteristics of binge drinking among 17,297 high school students aged 14 to 18 years were found to be associated with socioeconomic status in a study across the five different macro-regions of Brazil, where the prevalence of binge drinking was $32 \%$ in the previous year. Being in the highest socioeconomic status stratum doubled the risk of binge drinking among students in all five Brazilian macro-regions ${ }^{23}$. The first representative survey of binge drinking in Brazil, conducted in 143 Brazilian municipalities with subjects aged between 18 and 44 years, reported that most respondents had not engaged in binge drinking (69.7\%). Binge drinking was more common among participants who were male, single and had a higher family income ${ }^{24}$.

Binge drinking among youths is not an exclusively Brazilian phenomenon. In a Danish study involving individuals between 16 and 20 years of age, $74 \%$ of males and $59 \%$ of females reported having six or more drinks on a single occasion at least once a month ${ }^{25}$. Both the habitual and excessive consumption of alcohol in a short period of time (binge drinking) are essential factors in the analysis of intake amounts. Binge drinking has been widely described to be associated with physical, social and mental problems ${ }^{19}$. According to a longitudinal birth cohort study involving 11,622 subjects aged 16 years (11,261 of whom were followed up at 30 years of age), adolescent binge drinking predicted an increased risk of adult alcohol dependence, excessive regular alcohol consumption, illicit drug use, psychiatric illness, homelessness, school exclusion, lack of qualifications, accidents and a lower social class ${ }^{26}$. In another cohort study, alcohol dependence in young adults was preceded by a high frequency of alcohol consumption in adolescence; among the adolescents who reported binge drinking, the chance of belonging to the group of dependent individuals was 6.7-fold greater ${ }^{27}$.

The present study found no statistically significant difference by gender with regard to binge drinking. Previous literature has reported conflicting findings concerning gender differences $^{18,21}$. The growing consumption of alcoholic beverages among females is related to recent social advances among women, such as financial independence and the fact that adolescent girls 
Table 1. Distribution of sample according to prevalence of binge drinking and independent variables. Belo Horizonte, Brazil, 2010.

\begin{tabular}{|c|c|c|c|}
\hline \multirow{3}{*}{ Independent variables } & \multicolumn{2}{|c|}{ Binge drinking in the past year } & \multirow{3}{*}{ P-value } \\
\hline & Never & Less than monthly to daily & \\
\hline & n (\%) & $\mathbf{n}(\%)$ & \\
\hline \multicolumn{4}{|l|}{ Type of school } \\
\hline Public & $478(66.7)$ & $239(33.3)$ & 0.001 \\
\hline Private & $92(52.9)$ & $82(47.1)$ & \\
\hline \multicolumn{4}{|l|}{ Age } \\
\hline $15-16$ & $344(65.0)$ & $185(35.0)$ & 0.428 \\
\hline $17-19$ & $226(62.4)$ & $136(37.6)$ & \\
\hline \multicolumn{4}{|l|}{ Sex } \\
\hline Male & $215(61.1)$ & $137(38.9)$ & 0.146 \\
\hline Female & $355(65.9)$ & $184(34.1)$ & \\
\hline \multicolumn{4}{|l|}{ Mother schooling } \\
\hline $0-7$ years & $214(69.9)$ & $92(30.1)$ & 0.002 \\
\hline 8 or more years & $245(58.5)$ & $173(41.4)$ & \\
\hline \multicolumn{4}{|l|}{ Social Vulnerability Index } \\
\hline Greater vulnerability & $338(59.3)$ & $139(43.3)$ & 0.000 \\
\hline Lesser vulnerability & $232(40.7)$ & $182(56.7)$ & \\
\hline${ }^{\mathrm{T}}$ Trust in people & $32(56.1)$ & & \\
\hline People can be trusted & $538(64.5)$ & & 0.146 \\
\hline You can't be too careful & & $25(43.9)$ & \\
\hline${ }^{\top}$ Most people are willing to help if you need it & $192(69.1)$ & $296(35.5)$ & \\
\hline Agree & $138(61.9)$ & & 0.054 \\
\hline Neither agree or disagree & & $86(30.9)$ & \\
\hline Disagree & $240(61.5)$ & $85(38.1)$ & \\
\hline $\begin{array}{l}{ }^{\mathrm{T}} \text { One has to be alert or someone is likely to take } \\
\text { advantage of you }\end{array}$ & $150(38.5)$ & $150(38.5)$ & \\
\hline Agree & $428(64.1)$ & $240(35.9)$ & 0.905 \\
\hline Neither agree or disagree & $73(61.9)$ & $45(38.1)$ & \\
\hline Disagree & $69(65.7)$ & $36(34.3)$ & \\
\hline \multicolumn{4}{|l|}{${ }^{\mp}$ Trust in Local government officials } \\
\hline Trust to a great extent & $19(65.5)$ & $10(34.5)$ & 0.924 \\
\hline Neither great nor small extent & $173(63.4)$ & $100(36.6)$ & \\
\hline Trust to a small extent & $378(64.2)$ & $211(35.8)$ & \\
\hline \multicolumn{4}{|l|}{${ }^{\top}$ Central government officials } \\
\hline Trust to a great extent & $21(63.6)$ & $12(36.4)$ & \\
\hline Neither great nor small extent & $159(63.3)$ & $92(36.7)$ & 0.798 \\
\hline Trust to a small extent & $390(64.4)$ & $216(35.6)$ & \\
\hline \multicolumn{4}{|l|}{${ }^{\mathrm{T}}$ Contribute with time } \\
\hline Yes & $374(63.3)$ & $217(36.7)$ & \\
\hline No & $196(65.3)$ & $104(34.7)$ & 0.547 \\
\hline \multicolumn{4}{|l|}{${ }^{\mathrm{T}}$ Contribute with money } \\
\hline Yes & $192(63.6)$ & $110(36.4)$ & \\
\hline No & $378(64.2)$ & $211(35.8)$ & 0.860 \\
\hline \multicolumn{4}{|l|}{${ }^{\top}$ Participate in any communal activities } \\
\hline Yes & $158(58.3)$ & $113(41.7)$ & \\
\hline No & $412(66.5)$ & $208(33.5)$ & 0.020 \\
\hline \multicolumn{4}{|l|}{$\begin{array}{l}{ }^{{ }^{2}} \text { People will cooperate cooperate to try to solve a } \\
\text { water supply problem }\end{array}$} \\
\hline Likely & $337(66.9)$ & $167(33.1)$ & \\
\hline Neither likely or unlikely & $132(65.0)$ & $71(35.0)$ & 0.007 \\
\hline Unlikely & $101(54.9)$ & $83(45.1)$ & \\
\hline
\end{tabular}

${ }^{a}$ Chi-square test. ${ }^{\circledR}$ Questões do SC-IQ: Trust/Solidarity and Collective Action/Cooperation subscales. 
Table 2. Risk factor for binge drinking (Poisson logistic regression analysis ${ }^{\mathrm{a}}$ ); Belo Horizonte, Brazil, 2010.

\begin{tabular}{|c|c|c|c|c|c|}
\hline $\begin{array}{c}\text { Dependent } \\
\text { variable }\end{array}$ & $\begin{array}{c}\text { Independent } \\
\text { variable }\end{array}$ & $\begin{array}{c}\text { P-value } \\
\text { Crude }\end{array}$ & $\begin{array}{c}\mathrm{PR}^{\mathrm{a}} \text { 95\% CI } \\
\text { Crude } \\
\end{array}$ & $\begin{array}{l}\text { R 95\% CI }{ }^{b} \\
\text { Adjusted }^{\mathrm{a}}\end{array}$ & $\begin{array}{l}\text { P-value } \\
\text { Adjusted }\end{array}$ \\
\hline \multirow{16}{*}{$\begin{array}{l}\text { Binge } \\
\text { Drinking } \\
\text { in the past } \\
\text { year }\end{array}$} & Age & \multirow{3}{*}{0.426} & & & \multirow{3}{*}{0.050} \\
\hline & $15-16$ & & $0.931(0.780-1.111)$ & $0.837(0.700-1.000)$ & \\
\hline & $17-19$ & & 1 & 1 & \\
\hline & \multicolumn{5}{|l|}{ Sex } \\
\hline & Male & \multirow[t]{2}{*}{0.114} & $1.140(0.956-1.359)$ & $1.124(0.943-1.340)$ & \multirow[t]{2}{*}{0.191} \\
\hline & Female & & 1 & 1 & \\
\hline & Type of school & & & & \\
\hline & Public & \multirow[t]{2}{*}{$<0.001$} & $0.707(0.586-0.854)$ & $0.795(0.651-0.971)$ & \multirow[t]{2}{*}{0.025} \\
\hline & Private & & 1 & 1 & \\
\hline & Social Vulnerability Index & \multirow{3}{*}{$<0.001$} & & & \multirow{3}{*}{$<0.001$} \\
\hline & Greater SVI & & $0.663(0.555-0.791)$ & $0.689(0.570-0.834)$ & \\
\hline & Lesser SVI & & 1 & 1 & \\
\hline & $\begin{array}{l}\text { People will cooperate to } \\
\text { try to solve a water supply } \\
\text { problem }\end{array}$ & & & & \multirow{4}{*}{$\begin{array}{l}0.002 \\
0.103\end{array}$} \\
\hline & Likely & 0.048 & $0.804(0.648-0.998)$ & $0.728(0.598-0.887)$ & \\
\hline & Neither likely or unlikely & 0.933 & $0.991(0.804-1.222)$ & $0.814(0.635-1.042)$ & \\
\hline & Unlikely & & 1 & 1 & \\
\hline
\end{tabular}

PR: Prevalence ratio. ${ }^{\mathrm{b}} \mathrm{CI}$ : Confidence interval. ${ }^{\mathrm{c}}$ Adjusted for control variables (sex and age).

today have more freedom to frequent places that serve alcoholic beverages, which were previously restricted to men.

Farmer and Hanratty ${ }^{20}$, found a significant association between socioeconomic status and alcohol consumption, with adolescents from lower income families consuming more alcoholic beverages. Moreover, participants who reported greater family interactions were less likely to be regular users. Notably, the socioeconomic patterning of binge drinking in Brazil is opposite to that reported in the UK.

The SVI identifies where the most vulnerable populations live among the 81 administrative units that make up the city of Belo Horizonte. These spatial units delineate relatively homogeneous neighborhoods, with boundaries that often coincide with natural or constructed physical barriers ${ }^{10}$. A greater prevalence rate of binge drinking was found among adolescents with lower social vulnerability; those enrolled in private schools; and those whose mothers had attained a higher level of schooling. It is possible that higher economic status translates to greater purchasing power among socially privileged adolescents.

For adolescents with higher socioeconomic status, having greater financial resources may indicate that the relative cost of substance use is lower than that for adolescents from lower so- cioeconomic backgrounds ${ }^{14}$. According to Carlini-Cotrim and da Matta Chasin ${ }^{21}$, this is in contrast to the commonly held notion that private schools are more protected from certain problems, such as the consumption of psychoactive substances and violent behavior. Likewise, the findings reported in a previous study in the USA indicate that higher socioeconomic status (as measured by parental schooling and household income) in adolescence is associated with higher rates of substance use, particularly binge drinking ${ }^{11}$. Lower income leads to reduced consumption of all goods, including alcohol, due to the need to allocate resources for expenditures on different products ${ }^{28}$. In the present study, the association between greater engagement in binge drinking and higher socioeconomic status remained statistically significant in multivariate analysis. The different components of social capital encompass civic participation, collective efficacy and social ties. The IQ-SC measures feelings of collective efficacy and capacity that encourage members of a residential unit to exert an influence on local events. The Trust/Solidarity and Collective Action/Cooperation subscales were employed in the present study. Participation in community activities, which is one of the aspects of the structural component of social capital, assesses the likelihood that people can help each other to solve a community problem. 
Despite being protectively associated with binge drinking in bivariate analysis, this factor was not associated with such drinking in the Poisson regression model. These findings may be explained by cultural practices in Brazil, where it is common to drink socially after meetings and encounters involving community participation, as well as the easy access adolescents have to alcoholic beverages, despite the laws governing the sale of such products. However, none of the data in the present study on the use of alcoholic beverages during meetings explains the non-significance of the association with "participation in community activities" in the regression model.

Social capital can be measured by patterns of cooperation/collective action, volunteer work and associational life in a community, levels of social trust, reciprocity, mutual help among neighbors/ members of an association and degree of civic engagement. Trust, engagement and mutual obligation among individuals in a community are contextual factors that may offer protection from the harmful use of alcohol by adolescents. The level of trust among the members of a community is also related to informal participation in volunteer activities and can exert a positive influence on both wellbeing and longevity, including serving as a protective factor against the harmful use of alcohol. Social capital measured by cooperation and collective action through social participation has the capacity to increase or diminish alcohol intake, depending on the predominant drinking patterns and norms of the social group ${ }^{29}$.

In the present study, adolescents who perceived that people in their community are able to get together to solve a problem that affected everyone (such as a change in the public water supply) were less likely to engage in binge drinking. In a study involving 140 American universities, a greater level of social capital (as measured by involvement in volunteer activities) was associated with a significantly lower risk of binge drinking and associated harms, which underscores the importance of social contexts for young people. Among the risk factors for alcohol abuse, the researchers identified the accessibility, availability and price of alcoholic beverages ${ }^{29}$.

According to literature, when an individual engages in collective actions with the aim of benefiting the entire community, social capital is considered positive for the majority of members of that community ${ }^{8,30}$. Few studies have assessed the association between social participation, solidarity and alcohol consumption and/or abuse, especially among adolescents. In two prior publi- cations, high degrees of social participation combined with a low degree of trust were positively associated with excessive alcohol intake. Alcohol consumption may directly or indirectly affect health through its impact on the development of positive social networks ${ }^{31}$. Trade union membership, volunteering and social participation can be construed as either precursors or consequences of social capital, suggesting an urgent need to incorporate direct measures of social cohesion ${ }^{30}$.

In a systematic review of programs aimed at controlling risk behaviors among adolescents, such as alcohol use, drug use and sexual activity, the authors employed the Assessment of Multiple Systematic Reviews (AMSTAR) tool to assess the methodological quality of the studies and listed the actions that proved efficient in determining intervention strategies. The most promising programs considered a variety of risk and protection factors, such as boosting resilience and the promotion of positive influences from parents, family members and the school setting in providing healthy support to the social and emotional development of adolescents. The authors stress the need to broaden approaches on cultural and social levels ${ }^{32}$.

Knowledge of the consequences of early alcohol intake and binge drinking, such as involvement with other drugs, traffic accidents, violence and academic problems, health professionals, public policy developers, teachers and parents should increase efforts to track, monitor and prevent the initiation and excessive consumption of alcohol by children and adolescents ${ }^{33}$. The results of this study suggest that promoting solidarity and participation in activities that benefit the community may constitute tools for combating excessive alcohol consumption among adolescents. However, due to the complexity of this issue, the discussion on the topic should be broadened to include social movements and public administrators.

It is believed that through associations, people develop interactions with each other, increasing the possibility of mutual trust developing between them ${ }^{34}$. According to Veenstra et al..$^{35}$, social capital and health are embedded in the local geographical context and are influenced by demographic, socioeconomic and behavioral factors and skills for coping with problems. Whereas knowledge about heavy drinking in developing countries is limited ${ }^{12}$, the present study contributes to scientific advancement, identifying social characteristics that should be considered in strategies for the prevention of heavy drinking. 
The limitations of the present study are typical of cross-sectional surveys, especially with regard to causal inference and information bias. Even though anonymity was assured and self-administered questionnaires were used, it is possible that the adolescents did not reveal their true alcohol use patterns due to distrust, self-censorship, social desirability, feelings of guilt or memory lapses. Nonetheless, the present study offers a starting point for the development of longitudinal studies that can start to describe the influence of social factors and drinking behavior among young people.

\section{Collaborations}

KO Jorge contributed to the conception and design of the study, data collection, analysis and interpretation and drafting of the manuscript and approved of the final version for publication. PCP Paiva contributed to drafting of the manuscript and approved of the final version for publication. EF Ferreira, MP Vale, I Kawachi interpretation of the data and offered a critical review of the intellectual content and approved of the final version for publication. PM Zarzar contributed to the conception and design of the study, interpretation of the data and drafting of the manuscript, offered a critical review of the intellectual content and approved of the final version for publication.

\section{Acknowledgments}

The authors wish to thank the Brazilian fostering agency Fundação de Amparo à Pesquisa de Minas Gerais (FAPEMIG) for its support.

\section{Conclusions}

The findings of the present study reveal a high prevalence of alcohol consumption and binge drinking among adolescents in the city of Belo Horizonte, Brazil. Greater engagement in binge drinking was found among adolescents with a higher socioeconomic status. Moreover, a lower frequency of binge drinking was found among adolescents who reported higher stocks of social capital in their community, measured in terms of the willingness of residents to undertake collective action to solve common problems.

\section{References}

1. Senna SRCM, Dessen MA. Contribuições das Teorias do Desenvolvimento Humano para a Concepção Contemporânea da Adolescência. Psicol: Teoria e Pesquisa 2012; 28(1):101-108.

2. Wechsler H, Nelson TF. Binge drinking and the American college student: what's five drinks? Psychol Addict Behav 2001; 15(4):287-291.

3. McCambridge J, McAlaney J, Rowe R. Adult consequences of late adolescent alcohol consumption: a systematic review of cohort studies. PLoS Med 2011; 8:1000413.

4. Teevale T, Robinson E, Duffy S, Utter J, Nosa V, Clark $\mathrm{T}$, Sheridan J, Ameratunga S. Binge drinking and alcohol-related behaviours amongst Pacific youth: a national survey of secondary school students. $N Z$ Med J 2012; 125(1352):60-70.

5. Putnam RD. Bowling Alone. The Collapse and Revival of American Community. New York: Simon and Schuster; 2000.

6. Villalonga-Olives E, Kawachi I. The measurement of social capital. Gaceta Sanitaria 2015; 29(1):62-64.

7. Moreira MC. The dimensions of volunteer associativism in the scenario of the relationships amongst health, poverty and disease. Cien Saude Colet 2010; 15(3):917924.

8. Kawachi I, Kennedy BP, Glass R. Social capital and self-rated health: a contextual analysis. Am J Public Health 1999; 89(8):1187-1193.

9. Nahas MI, Ribeiro C, Esteves O, Moscovitch S, Martins VL. O mapa da exclusão social de Belo Horizonte: metodologia de construção de um instrumento de gestão urbana. Cad Cienc Soc 2000; 7(10):75-88. 
10. Belo Horizonte City Hall. The Social Vulnerability Index. [Internet site in Portuguese]. [cited 2011 Aug 23]. Available from: http://www.portal2.pbh.gov.br/pbh/ index.html.

11. Humensky JL. Are adolescents with high socioeconomic status more likely to engage in alcohol and illicit drug use in early adulthood? Subst Abuse Treat, Prev Policy 2010; 5(5):19.

12. Sanchez ZM, Martins SS, Opaleye ES, Moura YG, Locatelli DP, Noto AR. Social factors associated to binge drinking: a cross-sectional survey among Brazilian students in private high schools. BMC Public Health 2011; 31(11):201.

13. Grootaert C, Narayan D, Jones V, Woolcook M. Measuring social capital: an Integrated Questionnaire. Washington: World Bank; 2003.

14. Zarzar PM, Jorge KO, Oksanen T, Vale MP, Ferreira EF, Kawachi I. Association between binge drinking, type of friends and gender: a cross-sectional study among Brazilian adolescents. BMC Public Health 2012; 18(12):257.

15. Paiva PCP, Paiva HN, Lamounier JA, Ferreira EF, César CAS, Zarzar PM. Binge drinking among 12-yearold adolescent schoolchildren and its association with sex, socioeconomic factors and alcohol consumption by best friends and family members. Cien Saude Colet 2015; 20(11):3427-3435.

16. Reinert DF, Allen JP. The alcohol use disorders identification test: An update of research findings. Alcohol Clin Exp Res 2007; 31(2):185-199.

17. Moretti-Pires RO, Corradi-Webster CM. Adaptation and validation of the Alcohol Use Disorders Identification Test (AUDIT) for a river population in the Brazilian Amazon. Cad Saude Publica 2011; 27(3):497-509.

18. Silva EF, Pavani RA, Moraes MS, Chiaravalloti Neto F. Drug abuse prevalence among secondary school in São José do Rio Preto, São Paulo State, Brazil. Cad Saude Publica 2006; 22(6):1151-1158.

19. Miller JW, Naimi TS, Brewer RD, Jones SE. Binge drinking and associated health risk behaviors among high school students. Pediatrics 2007; 119(1):76-85.

20. Farmer S, Hanratty B. The relationship between subjective wellbeing, low income and substance use among schoolchildren in the north west of England: a cross-sectional study. J Public Health 2012; 34(4):512522.

21. Carlini-Cotrim B, da Matta Chasin AA. Blood alcohol content and death from fatal injury: a study in the metropolitan area of São Paulo, Brazil. J Psychoactive Drugs 2000; 32(3):269-275.

22. Galduróz JC, Sanchez ZV, Opaleye ES, Noto AR, Fonseca AM, Gomes PL, Carlini EA. Factors associated with heavy alcohol use among students in Brazilian capitals. Rev Saude Publica 2010; 44(2):267-273.

23. Sanchez ZN, Locatelli DP, Noto AR, Martins SS. Binge drinking among Brazilian students: a gradient of association with socioeconomic status in five geo-economics regions. Drug Alcohol Depend 2013; 127(0):87-93.
24. Castroand DS, Sanchez ZM, Zaleski M, Alves HN, Pinsky I, Caetano R, Laranjeira RR. Sociodemographic characteristics associated with binge drinking among Brazilians. Drug Alcohol Depend 2012; 126(12):272-276.

25. Bloomfield K, Grittner U, Rasmussen HB, Petersen HC. Socio-demographic correlates of alcohol consumption in the Danish general population. Scand J Public Health 2008; 36(6):580-588.

26. Viner RM, Taylor B. Adult outcomes of binge drinking in adolescence: findings from a UK national birth cohort. J Epidemiol Community Health 2007; 61(10):902907.

27. Bonomo YA, Bowes G, Coffey C, Carlin JB, Patton GC. Teenage drinking and the onset of alcohol dependence: a cohort study over seven years. Addiction 2004; 99(12):1520-1528.

28. Svensson M, Hagquist C. Adolescents alcohol-use and economic conditions: a multilevel analysis of data from a period with big economic changes. Eur J Health Econ 2010; 11(6):533-541.

29. Weitzman ER, Kawachi I. Giving means receiving: the protective effect of social capital on binge drinking on college campuses. Am J Public Health 2000; 90(12):1936-1939.

30. Kim D, Subramanian SV, Kawachi I. Social capital and physical health: a systematic review of the literature. In: Kawachi I, Subramanian SV, Kim D, editors. Social capital and health. New York: Springer; 2008. p. 39-190.

31. Lindström M. Social capital, the miniaturization of community and high alcohol consumption: a population-based study. Alcohol Alcohol 2005; 40(6):556-562.

32. Jackson CA, Henderson M, Frank JW, Haw SJ. An overview of prevention of multiple risk behaviour in adolescence and young adulthood. J Public Health 2012; 34(Supl. 1):i31-40.

33. Maggs JL, Staff J, Patrick ME, Wray-Lake L, Schulenberg JE. Alcohol Use at the Cusp of Adolescence: A Prospective National Birth Cohort Study of Prevalence and Risk Factors. J Adolesc Health 2015; 56(6):639-645.

34. Pattussi MP, Moysés SJ, Junges JR, Sheiham A. Social capital and the research agenda in epidemiology. Cad Saude Publica 2006; 22(8):1525-1546.

35. Veenstra G. Location, location, location: contextual and compositional health effects of social capital in British Columbia, Canada. Soc Sci Med 2005; 60(9):2059-2071.

Artigo apresentado em 07/03/2016

Aprovado em 09/06/2016

Versão final apresentada em 11/06/2016 